\title{
A unified model of time perception accounts for duration-based and beat-based timing mechanisms
}

\section{Sundeep Teki ${ }^{1}$ *, Manon Grube ${ }^{2}$ and Timothy D. Griffiths ${ }^{1,2}$}

${ }^{1}$ Wellcome Trust Centre for Neuroimaging, University College London, London, UK

2 Institute of Neuroscience, Newcastle University, Newcastle-upon-Tyne, UK

\section{Edited by:}

Warren H. Meck, Duke University, USA

\section{Reviewed by:}

Warren H. Meck, Duke University, USA

Michael Schwartze, Max Planck Society, Germany

\section{${ }^{*}$ Correspondence:}

Sundeep Teki, Wellcome Trust Centre for Neuroimaging, University College London, 12 Queen Square, London WC1N 3BG, UK.

e-mail: sundeep.teki.10@ucl.ac.uk
Accurate timing is an integral aspect of sensory and motor processes such as the perception of speech and music and the execution of skilled movement. Neuropsychological studies of time perception in patient groups and functional neuroimaging studies of timing in normal participants suggest common neural substrates for perceptual and motor timing. A timing system is implicated in core regions of the motor network such as the cerebellum, inferior olive, basal ganglia, pre-supplementary, and supplementary motor area, pre-motor cortex as well as higher-level areas such as the prefrontal cortex. In this article, we assess how distinct parts of the timing system subserve different aspects of perceptual timing. We previously established brain bases for absolute, duration-based timing and relative, beat-based timing in the olivocerebellar and striato-thalamo-cortical circuits respectively (Teki et al., 2011). However, neurophysiological and neuroanatomical studies provide a basis to suggest that timing functions of these circuits may not be independent. Here, we propose a unified model of time perception based on coordinated activity in the core striatal and olivocerebellar networks that are interconnected with each other and the cerebral cortex through multiple synaptic pathways. Timing in this unified model is proposed to involve serial beat-based striatal activation followed by absolute olivocerebellar timing mechanisms.

\section{Keywords: interval timing, time perception, timing mechanisms, cerebellum, striatum}

"No clock mechanism fulfills its purpose as a clock unless its activity is perceived by an observer, who understands the manner in which the clock possesses the attributes of the timekeeper."

(Gooddy, 1958)

Human brain function is rhythmically organized at several timescales, from low frequency delta waves to high frequency gamma oscillations (Basar et al., 2001; Cheng et al., 2008). Based on such observations, Gooddy (1958) first proposed that the nervous system possesses the anatomical bases and physiological mechanisms for representing time, and may function as a clock. Indeed, recent research suggests that neural ensembles have inherent capacity to decode time encoded in the underlying neural dynamics (Matell et al., 2003; Karmarkar and Buonomano, 2007; Sumbre et al., 2008; Jin et al., 2009; Buonomano and Laje, 2010; Karmarkar, 2011; MacDonald et al., 2011; Merchant et al., 2011).

Complementary to this, is the view that postulates a dedicated internal timekeeper (Treisman, 1963; Wing and Kristofferson, 1973; Church, 1984; Gibbon et al., 1984, 1997; Matell and Meck, 2000; Ivry and Schlerf, 2008). Neuropsychological and neuroimaging work has found evidence for timing mechanisms in several brain areas such as the cerebellum (Ivry and Keele, 1989; Ivry, 1993; Nichelli et al., 1996; Penhune et al., 1998; Xu et al., 2006; Lee et al., 2007; Gooch et al., 2010; Grube et al., 2010a,b; Teki et al., 2011), basal ganglia (Artieda et al., 1992; Pastor et al., 1992; Harrington et al., 1998; Grahn and Brett, 2007; Teki et al., 2011), pre-supplementary and supplementary motor area
(pre-SMA/SMA; Halsband et al., 1993; Shima and Tanji, 2000; Macar et al., 2004, 2006; Kotz and Schwartze, 2011), and premotor and prefrontal cortex (Oshio, 2011; for reviews see: Ivry et al., 2002; Lewis and Miall, 2003; Ivry and Spencer, 2004; Meck and Malapani, 2004; Buhusi and Meck, 2005; Meck, 2005; Grahn, 2009; Grondin, 2010; Wiener et al., 2010; Coull et al., 2011). Thus, motor areas might contain specialized timekeeping mechanisms necessary to coordinate temporally precise and structured movements (e.g., handwriting, typing, talking, and walking) as well as perceptual timing.

In this article, we consider the notion that "movement is time, expressed": motor structures must have access to timing information and accumulating evidence suggests that the motor structures themselves also act as "observers" of time (Gooddy, 1958). We specifically discuss how the neural architecture of the olivocerebellar and striato-thalamo-cortical networks might allow these to observe cortical dynamics and read out "auditory" time in the sub-second range.

\section{TIMING MECHANISMS}

Two distinct timing mechanisms in the human brain are suggested by a consideration of the coordination and timing of movements. Lesions of the cerebellum are known to impair the timing of voluntary movements and adversely affect the production of skilled movements (e.g., tapping to a rhythm) and perceptual tasks such as duration discrimination (Ivry et al., 1988, 2002). In an elegant series of experiments, Spencer et al. (2003) showed that patients 
with cerebellar damage were selectively impaired in producing discontinuous movements (intermittent circle drawing) without any impairment in producing rhythmic movements (continuous circle drawing). This dissociation was attributed to the inability of the patients to form an explicit representation of absolute time between successive events. Continuous movements lack an event structure and are suggested to depend on temporal regularities that reflect emergent activity in distinct brain areas such as the basal ganglia or the cortex (Spencer et al., 2003; Ivry and Spencer, 2004).

\section{DURATION-BASED VS. BEAT-BASED TIMING}

In line with this dissociation in motor timing mechanisms, we posited the existence of analogous mechanisms for perceptual timing: absolute, duration-based timing and relative, beat-based timing (Grube et al., 2010a,b; Teki et al., 2011). The perceptual distinction has been suggested by previous behavioral work (Monahan and Hirsch, 1990; Yee et al., 1994; Pashler, 2001; McAuley and Jones, 2003; Grahn and McAuley, 2009). Absolute, duration-based timing refers to the measurement of the absolute duration of discrete time intervals $\left(\Delta T_{\mathrm{i}}\right)$, while relative, beat-based timing refers to the measurement of the duration of time intervals relative to a temporal regularity such as beats $\left(\Delta T_{\mathrm{i}} / T_{\text {beat }}\right.$; Teki et al., 2011$)$.

The concept of beat-based perception of time can be traced back to William James who wrote that "subdividing the time by beats of sensation aids our accurate knowledge of the amount of it that elapses" (James, 1890, Vol. 1, p. 619). Improved accuracy of time perception based on beat-based stimuli has been demonstrated in a number of studies (Essens and Povel, 1985; Palmer and Krumhansl, 1990; Parncutt, 1994; Grube and Griffiths, 2009). Several studies have further demonstrated improved timing for regular compared to irregular sequences (e.g., Sakai et al., 1999; Patel et al., 2005; Grahn and Brett, 2007; Teki et al., 2011).

\section{NEURAL SUBSTRATES OF DURATION-BASED AND BEAT-BASED TIMING}

Here, we discuss the neural networks that mediate duration-based and beat-based timing mechanisms respectively.

Previous neuropsychological studies of patients with cerebellar damage established the role of the cerebellum in discrete encoding of time intervals (Ivry et al., 1988; Ivry and Keele, 1989; Nichelli et al., 1996). Recently, Grube et al. (2010a) developed a test-battery of stimuli and timing tasks that measured duration-based and beat-based perception of time. A group of patients with Spinocerebellar Ataxia type-6 (SCA-6) were tested. Unlike previous studies of patients with stroke, this patient group has a stereotyped pattern of cerebellar degeneration affecting the superior part of the cerebellum first. The patients showed a specific impairment on the duration-based timing tasks, which involved a comparison of the absolute duration of a test interval to a reference interval of fixed or variable duration. However, they showed no deficits on the tasks comprising rhythmic sequences with a regular beat. This dissociation specifically implicated the cerebellum in the explicit encoding of the absolute duration of time intervals. These results motivated a follow-up study based on the same experimental stimuli in normal participants with temporary impairment of superior medial cerebellar function produced by continuous transcranial magnetic theta-burst stimulation (TBS; Grube et al., 2010b). The comparison of post- vs. pre-stimulation thresholds revealed a similar deficit only for the absolute timing task and not the rhythmic timing tasks.

Perception of rhythmic sequences with a regular beat has been studied in Parkinson's patients with an impaired nigrostriatal dopaminergic system, implicating the striatum in beat-based perception of time (Artieda et al., 1992; Pastor et al., 1992; Harrington et al., 1998). Functional magnetic resonance imaging (fMRI) studies of normal participants have further implicated the basal ganglia and pre-SMA/SMA in rhythm and beat perception. Grahn and Brett (2007) developed a test-battery of rhythmic sequences based on simple metrical, complex metrical or irregular, non-metrical ratios. A rhythm reproduction task revealed significantly better performance for the simple metrical sequences and functional imaging demonstrated bilateral increases in activity in the putamen during the simple metrical task. Subsequent work examining differences in functional activations between a beat and no-beat condition confirmed the role of the putamen and the SMA in the perception of rhythmic sequences with a regular beat (Grahn, 2009; Grahn and Rowe, 2009). Greater activity in the putamen associated with less salient beat markers was interpreted in terms of an internal beat prediction mechanism (Grahn and Rowe, 2009).

\section{FUNCTIONAL DISSOCIATION OF NETWORKS MEDIATING DURATION-BASED AND BEAT-BASED TIMING}

Previous work focused on either duration-based or beat-based timing mechanisms in isolation and did not directly compare the two mechanisms using a common perceptual timing task. The stimuli for the duration-based and beat-based timing tasks used by Grube et al. (2010a,b) were not matched for the total number of intervals and stimulus duration, while the beat-based timing work by Grahn and colleagues did not involve an explicit timing task (Grahn and Brett, 2007; Grahn and Rowe, 2009).

In order to resolve these issues, and to examine the contribution of the cerebellar and striatal networks to timing, we developed a novel stimulus and timing task (Teki et al., 2011; stimuli available online at: http://www.fil.ion.ucl.ac.uk/ steki). Stimuli (Figure 1A) consisted of a sequence of intervals that induced a varying temporal context that was either regular (isochronous) or irregular (incorporating 15\% jitter). Participants were required to compare the duration of the last to the second-to-last interval for both sequences. The time difference between the last and second-to-last intervals was adjusted to obtain similar accuracy for the regular and irregular sequences. We hypothesized that the timing of intervals in irregular sequences would recruit durationbased timing mechanisms as each interval has to be measured anew to perform the task. In contrast, the timing of regular sequences with a regular beat was predicted to involve beat-based timing mechanisms. The results revealed a clear functional dissociation such that an olivocerebellar network comprising the inferior olive and the cerebellum, including the dentate nucleus and vermis, was more active for duration-based timing and a striato-thalamocortical network comprising the putamen, caudate, thalamus, preSMA/SMA, premotor, and dorsolateral prefrontal cortex was more active for beat-based timing (Teki et al., 2011).

These results are consistent with previous work implicating the inferior olive (Xu et al., 2006; Liu et al., 2008; Wu et al., 2011), 


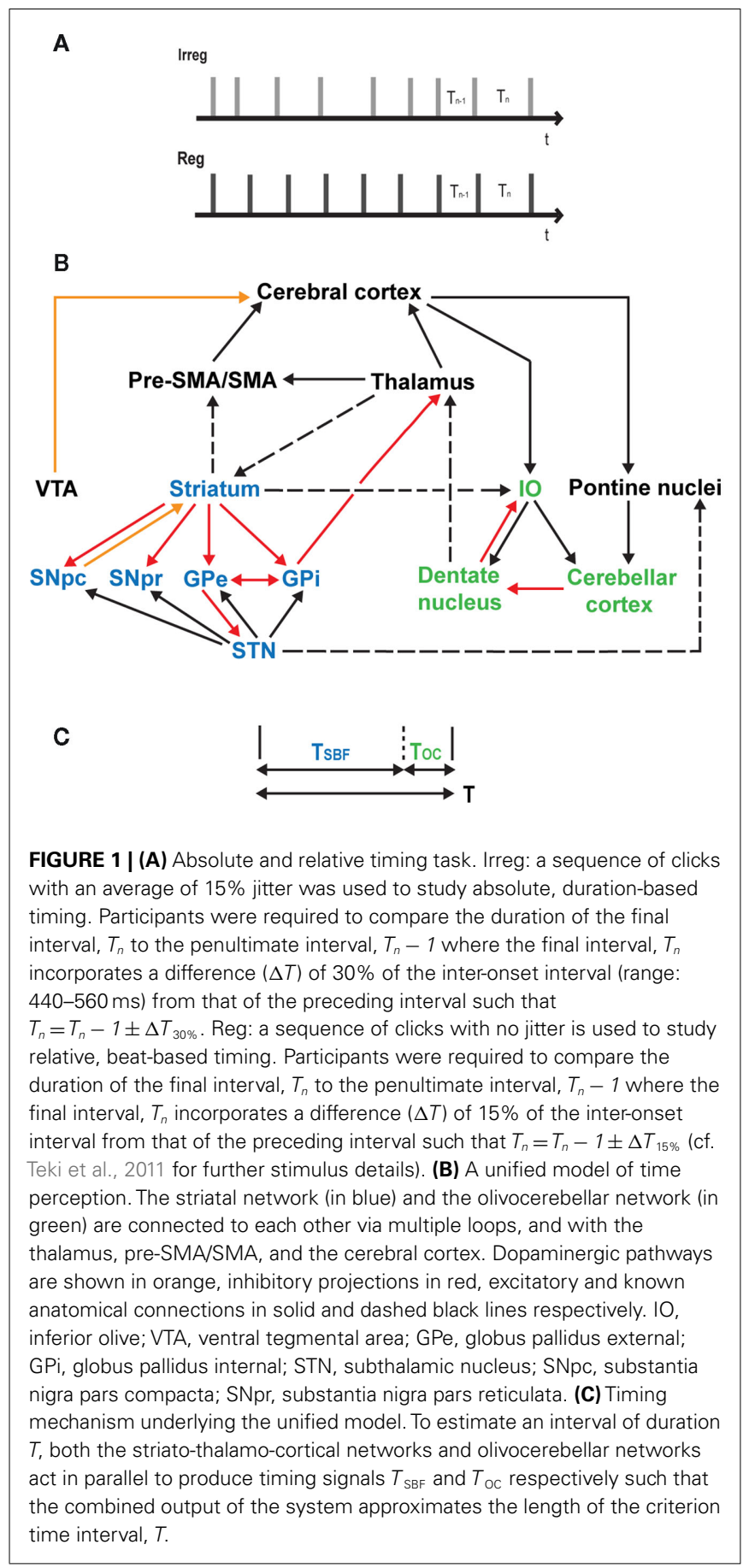

the cerebellum (reviewed above), and the striato-thalamo-cortical system (Matell and Meck, 2000, 2004; MacDonald and Meck, 2004; Buhusi and Meck, 2005; Meck, 2006a,b; Meck et al., 2008) in timing and time perception.

\section{NEUROPHYSIOLOGICAL BASES OF OLIVOCEREBELLAR AND STRIATAL TIMING SIGNALS}

In this section, we review the neurophysiological bases for the timing signals that are measured in the two different parts of the timing system.
The inferior olive represents the sole source of climbing fiber input to the Purkinje cells of the cerebellar cortex. Olivary cells possess unique cellular characteristics such as voltage-gated conductances that display rhythmic sub-threshold membranepotential oscillations at 5-15 Hz (Llinás and Yarom, 1981) as well as electrical gap-junctions. This electrical coupling helps to synchronize the membrane-potential oscillations and results in clusters of neurons in which activity is temporally coherent (Llinas et al., 1974). The deep cerebellar nuclei including the dentate nucleus, which represents the main output of the cerebellum, modulate the electrical coupling coefficient by inhibiting and decoupling the olivary cells into dynamic cell assemblies. The feed-forward inhibitory loop is closed by the Purkinje cells which inhibit the deep cerebellar nuclei. This unique organization in the olivocerebellar system results in the formation of a dynamic network capable of generating accurate absolute timing signals (Welsh et al., 1995; Yarom and Cohen, 2002; Jacobson et al., 2008; Mathy et al., 2009).

A possible physiological basis for a timing signal generated by the striato-thalamo-cortical circuits is described by the Striatal Beat Frequency (SBF) model which posits that the medium spiny neurons (MSNs) in the dorsal striatum monitor oscillatory activity $(5-15 \mathrm{~Hz})$ in the cerebral cortex and act as coincidence detectors (Miall, 1989; Matell and Meck, 2000, 2004; Meck et al., 2008; Agostino et al., 2011; Oprisan and Buhusi, 2011). Phasic dopamine release from the ventral tegmental area synchronizes the cortical oscillators at interval onset, while the dorsal striatum is modulated by dopaminergic input from the substantia nigra (Buhusi and Meck, 2005; Allman and Meck, 2011). Experience-dependent modulation of cortico-striatal synapses via mechanisms of longterm potentiation and long-term depression improves the reliability of coincidental activation of MSNs. Over repeated stimulus presentations in the form of a regular sequence of time intervals, the MSNs might learn to reliably predict the offset of the criterion interval and encode its duration via mechanisms of dopamine-mediated reinforcement signals: a specialized mechanism for timing analysis in a predictable, beat-based context (see Gu et al., 2011; Jones and Jahanshahi, 2011).

\section{A UNIFIED MODEL OF TIME PERCEPTION}

The current state of time perception research suggests that time is represented in a distributed manner and that time may be encoded in the population dynamics in each brain area or by a dedicated internal clock. The results from our fMRI study (Teki et al., 2011) support the notion that time is represented in a context-sensitive manner and depending on the temporal structure of time intervals, the olivocerebellar system or the striato-thalamo-cortical system may mediate timing functions.

The immediate question the work raises is whether there is one timing system or two and can the striatal and olivocerebellar systems be incorporated into a unified system? We attempt such a synthesis here: a unified model can be based on coordinated timing processes (as described above) in the striato-thalamo-cortical and olivocerebellar networks which are strongly connected with each other and the cortex through multi-synaptic loops and may act in parallel to improve the precision of the timing signal (see Meck, 2005; Allman and Meck, 2011 for a review). 
The unified model is illustrated in Figure 1B and shows the connections between the core striatal and olivocerebellar networks and the cerebral cortex. The basal ganglia and the cerebellum are connected through multiple loops with disynaptic projections from the dentate nucleus to the striatum via the thalamus and from the subthalamic nucleus to the cerebellar cortex via the pontine nuclei (Hoshi et al., 2005; Bostan and Strick, 2010; Bostan et al., 2010). The inferior olive receives auditory input from the cochlear nucleus (Kandler and Herbert, 1991) and bilateral afferents from the striatum (Walberg, 1956). The dentate nucleus sends projections to the premotor/motor cortex, and to the prefrontal and posterior parietal cortex via anatomically segregated "motor" and "cognitive" output channels (Middleton and Strick, 2001). The internal segment of the globus pallidus, which represents the output of the basal ganglia also sends segregated projections to the motor and prefrontal cortex (Middleton and Strick, 2002). Furthermore, pre-SMA and SMA receive connections from the striatum (Jürgens, 1984) and the dentate nucleus (Akkal et al., 2007) and may serve as a temporal accumulator (Casini and Vidal, $2011-$ but see Kononowicz and van Rijn, 2011; van Rijn et al., 2011).

\section{TIMING IN THE UNIFIED MODEL}

We assume that the coincidental activation of striatal MSNs as established by the SBF model represents the timing signal of the beat-based clock, and that the olivocerebellar system generates a timing signal corresponding to the duration-based clock. Furthermore, concordant with the fMRI results (Teki et al., 2011), the beat-based clock is assumed to be activated more when the stimuli are embedded in a predictable beat-based context and the duration-based clock is assumed to be more active for stimuli in an irregular or isolated context.

Suppose a single time interval of duration $T$ is to be timed as shown in Figure 1C. The beat-based clock is assumed to be the default clock of the brain and generates a timing signal which encodes a duration $T_{\mathrm{SBF}}$ such that $T=T_{\mathrm{SBF}}+\Delta T$, where $T_{\mathrm{SBF}}$ is the time corresponding to the SBF model and $\Delta T$ represents the error in time measurement. Complementary to its role in monitoring and optimizing movements, we propose that the olivocerebellar system possesses the neural architecture to provide a similar error-correction function for perceptual timing by encoding the duration $T_{\mathrm{OC}}$ (where, $T_{\mathrm{OC}}=\Delta T$ ) so that the output of the combined system approximates the original time interval, $T$. There are a number of auditory inputs to the striatum (Hikosaka et al., 1989; Bordi and LeDoux, 1992; Bordi et al., 1993; Yeterian and Pandya, 1998) and the cerebellum (Snider and Stowell, 1944; Azizi et al., 1985; Huang and Liu, 1985; Schmahmann, 1997; Petacchi et al., 2005; Kotz and Schwartze, 2010) which might allow direct comparison of the internally represented time interval and the actual time interval presented and this information may be fed to the cortex where attention and memory demands may modulate the timing signals.

Here, we extend the unified model to consider responses to a sequence of time intervals. If the interval $T$ is presented in a regular sequence of intervals, the estimates of $T_{\mathrm{SBF}}$ may improve with reinforcement resulting in smaller errors in encoding $T$, thereby minimizing the role of the olivocerebellar system. This is congruent with greater activation of the striato-thalamo-cortical network in the timing of beat-based sequences (Teki et al., 2011). On the other hand, if random jitter is incorporated into the interval $T$ on each occurrence, and repeated through an irregular sequence of intervals, estimates of $T_{\mathrm{SBF}}$ in this unpredictable context would be less accurate and result in larger errors in estimation of $T$. This may result in enhanced activation of the olivocerebellar system to encode the timing errors and is consistent with greater activity in this network for timing of irregular sequences (Teki et al., 2011). Such coordinated activity between the interconnected striatothalamo-cortical and olivocerebellar networks could form the bases of an optimal timing system that can read out accurate time.

Lastly, we consider the predictions of the model vis-à-vis neuropsychological work based on both duration-based and beatbased timing tasks. The default mode of the unified model is based on relative timing mechanisms in the striatum. According to this prediction, disruption of cerebellar mechanisms should leave relative timing intact; this is consistent with unimpaired relative timing performance observed in acute (TBS over medial cerebellum; Grube et al., 2010b) and chronic (SCA-6; Grube et al., 2010a) cases of cerebellar disruption. The unified model is asymmetrical in that the absolute timing mechanisms in the cerebellum finesse the more adaptive relative timing mechanisms in the striatum. The question that arises, then, is whether a double dissociation is possible and relative timing mechanisms might exist in isolation. The model developed here suggests that "pure" striatal lesions should result in deficits on both absolute and relative timing tasks, and this prediction is consistent with initial results from timing tests on patients with Parkinson's disease (Grube et al., 2010c), Huntington's Disease, and the striatal form of Multiple System Atrophy (Cope et al., 2011).

\section{CONCLUSION}

The unified timing model, based on the common activation of the striato-thalamo-cortical and olivocerebellar networks is consistent with their role in time perception as well as the specific motor and perceptual timing deficits observed in clinical populations. The model assumption of serial beat-based striatal activation followed by absolute olivocerebellar timing mechanisms shares some formal similarity to models of pitch and melody perception in which contour is processed before absolute pitch value in a serial fashion (Dowling et al., 1995). The two connected networks possess the mechanisms to mediate timing as proposed but the exact nature and time course of information flow through the inter-connected network remains to be elucidated. A systems-level investigation of these circuits using techniques such as simultaneous recording from olivocerebellar and striatal populations and targeted stimulation using two-photon fluorescence imaging or optogenetics (Cheng et al., 2011; Yizhar et al., 2011) at the cellular level, or analysis of effective connectivity between these brain networks using dynamic causal modeling of functional imaging data (Friston et al., 2003) may help obtain a better understanding of the neural mechanisms and substrates underlying timing and time perception.

\section{ACKNOWLEDGMENTS}

Sundeep Teki and Timothy D. Griffiths are supported by the Wellcome Trust, UK. 


\section{REFERENCES}

Agostino, P. V., Golombek, D. A., and Meck, W. H. (2011). Unwinding the molecular basis of interval and circadian timing. Front. Integr. Neurosci. 5:64. doi:10.3389/fnint.2011.00064

Akkal, D., Dum, R. P., and Strick, P. L. (2007). Supplementary motor area and presupplementary motor area: targets of basal ganglia and cerebellar output. J. Neurosci. 27, 10659-10673.

Allman, M. J., and Meck, W. H. (2011). Pathophysiological distortions in time perception and timed performance. Brain (in press). doi:10.1093/brain/awr210

Artieda, J., Pastor, M. A., Lacruz, F., and Obeso, J. A. (1992). Temporal discrimination is abnormal in Parkinson's disease. Brain 115, 199-210.

Azizi, S. A., Burne, R. A., and Woodward, D. J. (1985). The auditory corticopontocerebellar projection in the rat: inputs to the paraflocculus and midvermis. An anatomical and physiological study. Exp. Brain Res. 59, 36-49.

Basar, E., Basar-Eroglu, C., Karakas, S., and Schurmann, M. (2001). Gamma, alpha, delta, and theta oscillations govern cognitive processes. Int. J. Psychophysiol. 39, 241-248.

Bordi, F., and LeDoux, J. (1992). Sensory tuning beyond the sensory system: an initial analysis of auditory response properties of neurons in the lateral amygdaloid nucleus and overlying areas of the striatum. J. Neurosci. 12, 2493-2503.

Bordi, F., LeDoux, J., Clugnet, M. C., and Pavlides, C. (1993). Single-unit activity in the lateral nucleus of the amygdala and overlying areas of the striatum in freely behaving rats: rates, discharge patterns, and responses to acoustic stimuli. Behav. Neurosci. 107, 757-769.

Bostan, A. C., Dum, R. P., and Strick, P. L. (2010). The basal ganglia communicate with the cerebellum. Proc. Natl. Acad. Sci. U.S.A. 107, 8452-8456.

Bostan, A. C., and Strick, P. L. (2010). The cerebellum and basal ganglia are interconnected. Neuropsychol. Rev. 20, 261-270.

Buhusi, C. V., and Meck, W. H. (2005). What makes us tick? Functional and neural mechanisms of interval timing. Nat. Rev. Neurosci. 6, 755-765.

Buonomano, D. V., and Laje, R. (2010). Population clocks: motor timing with neural dynamics. Trends Cogn. Sci. (Regul. Ed.) 14, 520-527.

Casini, L., and Vidal, F. (2011). The SMAs: neural substrate of the temporal accumulator?
Front. Integr. Neurosci. 5:35. doi:10.3389/fnint.2011.00035

Cheng, R., Jesuthasan, S., and Penney, T. B. (2011). Time for zebrafish. Front. Integr. Neurosci. 5:40. doi:10.3389/fnint.2011.00040

Cheng, R. K., Williams, C. L., and Meck, W. H. (2008). Oscillatory bands, neuronal synchrony and hippocampal function: implications of the effects of prenatal choline supplementation for sleep-dependent memory consolidation. Brain Res. 1237, 176-194.

Church, R. M. (1984). Properties of the internal clock. Ann. N. Y. Acad. Sci. 423, 566-582.

Cope, T. E., Grube, M., Singh, B., Burn, D. J., and Griffiths, T. D. (2011). The basal ganglia in perceptual timing: timing performance in multiple systems atrophy. Abstr. Soc. Neurosci. 476.07.

Coull, J. T., Cheng, R.-K., and Meck, W. H. (2011). Neuroanatomical and neurochemical substrates of timing. Neuropsychopharmacology 36, 3-25.

Dowling, W. J., Kwak, S., and Andrews, M. W. (1995). The time course of recognition of novel melodies. Percept. Psychophys. 57, 136-149.

Essens, P. J., and Povel, D. J. (1985). Metrical and nonmetrical representations of temporal patterns. Percept. Psychophys. 37, 1-7.

Friston, K. J., Harrison, L., and Penny, W. (2003). Dynamic causal modelling. Neuroimage 19, 1273-1302.

Gibbon, J., Church, R. M., and Meck, W. H. (1984). Scalar timing in memory. Ann. N. Y. Acad. Sci. 423, 52-77.

Gibbon, J., Malapani, C., Dale, C. L., and Gallistel, C. (1997). Toward a neurobiology of temporal cognition: advances and challenges. Curr. Opin. Neurobiol. 7, 170-184.

Gooch, C. M., Wiener, M., Wencil, E. B., and Coslett, H. B. (2010). Interval timing disruptions in subjects with cerebellar lesions. Neuropsychologia 48, 1022-1031.

Gooddy, W. (1958). Time and the nervous system: the brain as a clock. Lancet 1, 1139-1144.

Grahn, J. A. (2009). The role of the basal ganglia in beat perception: neuroimaging and neuropsychological investigations. Ann. N. Y. Acad. Sci. 1169, 35-45.

Grahn, J. A., and Brett, M. (2007). Rhythm and beat perception in motor areas of the brain. J. Cogn. Neurosci. 19, 893-906.

Grahn, J. A., and McAuley, J. D. (2009). Neural bases of individual differences in beat perception. Neuroimage 47, 1894-1903.
Grahn, J. A., and Rowe, J. B. (2009). Feeling the beat: premotor and striatal interactions in musicians and nonmusicians during beat perception. $J$. Neurosci. 29, 7540-7548.

Grondin, S. (2010). Timing and time perception: a review of recent behavioral and neuroscience findings and theoretical directions. Atten. Percept. Psychophys. 72, 561-582.

Grube, M., Cooper, F. E., Chinnery, P. F. and Griffiths, T. D. (2010a). Dissociation of duration-based and beatbased auditory timing in cerebellar degeneration. Proc. Natl. Acad. Sci. U.S.A. 107, 11597-11601.

Grube, M., Lee, K.-H., Griffiths, T. D. Barker, A. T., and Woodruff, P. W. (2010b). Transcranial magnetic theta-burst stimulation of the human cerebellum distinguishes absolute, durationbased from relative, beat-based perception of subsecond time intervals. Front. Psychol. 1:171. doi:10.3389/fpsyg.2010.00171

Grube, M., Cooper, F. E., Mandal, A. Cope, T., Burn, D. J., and Griffiths, T. D. $(2010 \mathrm{c})$. The basal ganglia in perceptual timing: the effects of Parkinson's disease and deep-brain stimulation. Abst. Soc. Neurosci. 324.6.

Grube, M., and Griffiths, T. D. (2009). Metricality-enhanced temporal encoding and the subjective perception of rhythmic sequences. Cortex 45, 72-29.

$\mathrm{Gu}$, B. M., Yin, B., Cheng, R. K., and Meck, W. H. (2011). Quinpirole-induced sensitization to noisy/sparse periodic input: temporal synchronization as a component of obsessive-compulsive disorder. Neuroscience 179, 143-150.

Halsband, U., Ito, N., Tanji, J., and Freund, H. J. (1993). The role of premotor cortex and the supplementary motor area in the temporal control of movement in man. Brain 116, 243-266.

Harrington, D. L., Haaland, K. Y., and Hermanowicz, N. (1998). Temporal processing in the basal ganglia. Neuropsychology 12, 3-12.

Hikosaka, O., Sakamoto, M., and Usui, S. (1989). Functional properties of monkey caudate neurons. II. Visual and auditory responses. J. Neurophysiol. 61, 799-813.

Hoshi, E., Tremblay, L., Féger, J., Carras, P. L., and Strick, P. L. (2005) The cerebellum communicates with the basal ganglia. Nat. Neurosci. 8 , 1491-1493.

Huang, C.-M., and Liu, G. (1985). Electrophysiological mapping of the auditory areas in the cerebellum of the cat. Brain Res. 335, 121-129.
Ivry, R. (1993). Cerebellar involvement in the explicit representation of temporal information. Ann. N. Y. Acad. Sci. 682, 214-230.

Ivry, R. B., and Keele, S. W. (1989). Timing functions of the cerebellum. $J$. Cogn. Neurosci. 1, 136-152.

Ivry, R. B., Keele, S. W., and Diener, H. C. (1988). Dissociation of the lateral and medial cerebellum in movement timing and movement execution. Exp. Brain Res. 73, 167-180.

Ivry, R. B., and Schlerf, J. E. (2008). Dedicated and intrinsic models of time perception. Trends Cogn. Sci. (Regul. Ed.) 12, 273-280.

Ivry, R. B., Spencer, R. M., Zelaznik, H. N., and Diedrichsen, J. (2002). The cerebellum and event timing. Ann. N. Y. Acad. Sci. 978, 302-317.

Ivry, R. B., and Spencer, R. M. C. (2004). The neural representation of time. Curr. Opin. Neurobiol. 14, 225-232.

Jacobson, G. A., Rokni, D., and Yarom, Y. (2008). A model of the olivocerebellar system as a temporal pattern generator. Trends Neurosci. 31, 617-625.

James, W. (1890). The Principles of Psychology, Vol. 1. New York: Henry Holt.

Jin, D. Z., Fujii, N., and Graybiel, A. M. (2009). Neural representation of time in cortico-basal ganglia circuits. Proc. Natl. Acad. Sci. U.S.A. 106, 19156-19161

Jones, C. R. G., and Jahanshahi, M. (2011). Dopamine modulates striato-frontal functioning during temporal processing. Front. Integr. Neurosci. 5:70. doi:10.3389/fnint.2011.00070

Jürgens, U. (1984). The efferent and afferent connections of the supplementary motor area. Brain Res. 300 63-81.

Kandler, K., and Herbert, H. (1991). Auditory projections from the cochlear nucleus to pontine and mesencephalic reticular nuclei in the rat. Brain Res. 562, 230-242.

Karmarkar, U. R. (2011). Defining the contributions of network clock models to millisecond timing. Front. Integr. Neurosci. 5:41. doi:10.3389/fnint.2011.00041

Karmarkar, U. R., and Buonomano, D. V. (2007). Timing in the absence of clocks: encoding time in neural network states. Neuron 53, 427-438.

Kononowicz, T. W., and van Rijn, H. (2011). Slow potentials in time estimation: the role of temporal accumulation and habituation. Front. Integr. Neurosci. 5:48. doi:10.3389/fnint.2011.00048 
Kotz, S. A., and Schwartze, M. (2010). Cortical speech processing unplugged: a timely subcorticocortical framework. Trends Cogn. Sci. (Regul. Ed.) 14, 392-399.

Kotz, S. A., and Schwartze, M. (2011). Differential input of the supplementary motor area to a dedicated temporal processing network: functional and clinical implications. Front. Integr. Neurosci. 5:86. doi:10.3389/fnint.2011.00086

Lee, K.-H., Egleston, P. N., Brown, W. H., Gregory, A. N., Barker, A. T., and Woodruff, P. W. R. (2007). The role of the cerebellum in subsecond time perception: evidence from repetitive transcranial magnetic stimulation. J. Cogn. Neurosci. 19, 147-157.

Lewis, P. A., and Miall, R. C. (2003). Distinct systems for automatic and cognitively controlled time measurement: evidence from neuroimaging. Curr. Opin. Neurobiol. 13, 250-255.

Liu, T., Xu, D., Ashe, J., and Bushara, K. (2008). Specificity of inferior olive response to stimulus timing. J. Neurophysiol. 100, 1557-1561.

Llinas, R., Baker, R., and Sotelo, C. (1974). Electrotonic coupling between neurons in cat inferior olive. J. Neurophysiol. 37, 560-571.

Llinás, R., and Yarom, Y. (1981). Electrophysiology of mammalian inferior olivary neurones in vitro. Different types of voltage-dependent ionic conductances. J. Physiol. (Lond.) 315, 549-567.

Macar, F., Anton, J.-L., Bonnet, M., and Vidal, F. (2004). Timing functions of the supplementary motor area: an event-related fMRI study. Brain Res. Cogn. Brain Res. 206-215.

Macar, F., Coull, J., and Vidal, F. (2006). The supplementary motor area in motor and perceptual timing: fMRI studies. Cogn. Process. 7, 89-94.

MacDonald, C. J., Lepage, K. Q., Eden, U. T., and Eichenbaum, H. (2011). Hippocampal "time cells" bridge the gap in memory for discontiguous events. Neuron 71, 737-749.

MacDonald, C. J., and Meck, W. H. (2004). Systems-level integration of interval timing and reaction time. Neurosci. Biobehav. Rev. 28, 747-769.

Matell, M. S., and Meck, W. H. (2000). Neuropsychological mechanisms of interval timing behavior. Bioessays 22, 94-103.

Matell, M. S., and Meck, W. H. (2004). Cortico-striatal circuits and interval timing: coincidence detection of oscillatory processes. Brain Res. Cogn. Brain Res. 21, 139-170.
Matell, M. S., Meck, W. H., and Nicolelis, M. A. L. (2003). Interval timing and the encoding of signal duration by ensembles of cortical and striatal neurons. Behav. Neurosci. 117, 760-773.

Mathy, A., Ho, S. S. N., Davie, J. T., Duguid, I. C., Clark, B. A., and Häusser, M. (2009). Encoding of oscillations by axonal bursts in inferior olive neurons. Neuron 62, 388-399.

McAuley, J. D., and Jones, M. R. (2003). Modeling effects of rhythmic context on perceived duration: a comparison of interval and entrainment approaches to short-interval timing. J. Exp. Psychol. Hum. Percept. Perform. 29, 1102-1125.

Meck, W. H. (2005). Neuropsychology of timing and time perception. Brain Cogn. 58, 1-8.

Meck, W. H. (2006a). Frontal cortex lesions eliminate the clock speed effect of dopaminergic drugs on interval timing. Brain Res. 1108, 157-167.

Meck, W. H. (2006b). Neuroanatomical localization of an internal clock: a functional link between mesolimbic, nigrostriatal, and mesocortical dopaminergic systems. Brain Res. 1109, 93-107.

Meck, W. H., and Malapani, C. (2004). Neuroimaging of interval timing. Brain Res. Cogn. Brain Res. 21, 133-137.

Meck, W. H., Penney, T. B., and Pouthas, V. (2008). Cortico-striatal representation of time in animals and humans. Curr. Opin. Neurobiol. 18, 145-152.

Merchant, H., Zarco, W., Pérez, O., Prado, L., and Bartolo, R. (2011). Measuring time with different neural chronometers during a synchronization-continuation task. Proc. Natl. Acad. Sci. U.S.A. (in press). doi: $10.1073 /$ pnas. 1112933108

Miall, R. C. (1989). The storage of time intervals using oscillating neurons. Neural Comput. 1, 359-371.

Middleton, F. A., and Strick, P. L. (2001). Cerebellar projections to the prefrontal cortex of the primate. J. Neurosci. 21, 700-712.

Middleton, F. A., and Strick, P. L. (2002). Basal-ganglia "projections" to the prefrontal cortex of the primate. Cereb. Cortex 12, 926-935.

Monahan, C. B., and Hirsch, I. J. (1990). Studies in auditory timing: 2. rhythm patterns. Percept. Psychophys. 47, 227-242.

Nichelli, P., Alway, D., and Grafman, J. (1996). Perceptual timing in cerebellar degeneration. Neuropsychologia 34, 863-871.
Oprisan, S. A., and Buhusi, C. V. (2011). Modeling pharmacological clock and memory patterns of interval timing in a striatal beatfrequency model with realistic, noisy neurons. Front. Integr. Neurosci. 5:52. doi:10.3389/fnint.2011.00052

Oshio, K.-I. (2011). Possible functions of prefrontal cortical neurons in duration discrimination. Front. Integr. Neurosci. 5:25. doi:10.3389/fnint.2011.00025

Palmer, C., and Krumhansl, C. L. (1990). Mental representations for musical meter. J. Exp. Psychol. Hum. Percept. Perform. 16, 728-741.

Parncutt, R. (1994). A perceptual model of pulse salience and metrical accent in musical rhythm. Music Percept. 11 , 409-464.

Pashler, H. (2001). Perception and production of brief durations: beatbased versus interval-based timing. J. Exp. Psychol. Hum. Percept. Perform. 27, 485-493.

Pastor, M. A., Artieda, J., Jahanshahi, M. and Obeso, J. A. (1992). Time estimation and reproduction is abnormal in Parkinson's disease. Brain $115,211-225$

Patel, A. D., Iversen, J. R., Chen, Y., and Repp, B. H. (2005). The influence of metricality and modality on synchronization with a beat. Exp. Brain Res. 163, 226-238.

Penhune, V. B., Zattore, R. J., and Evans, A. C. (1998). Cerebellar contributions to motor timing: a PET study of auditory and visual rhythm reproduction. J. Cogn. Neurosci. 10 , 752-765.

Petacchi, A., Laird, A. R., Fox, P. T. and Bower, J. M. (2005). Cerebellum and auditory function: an ALE metaanalysis of functional neuroimaging studies. Hum. Brain Mapp. 25, 118-128.

Sakai, K., Hikosaka, O., Miyauchi, S., Takino, R., Tamada, T., Iwata, N. K., and Nielsen, M. (1999). Neural representation of a rhythm depends on its interval ratio. J. Neurosci. 19, 10074-10081.

Schmahmann, J. D. (1997). The Cerebellum and Cognition. New York: Academic Press.

Shima, K., and Tanji, J. (2000). Neuronal activity in the supplementary and presupplementary motor area for temporal organization of multiple movements. J. Neurophysiol. 84, 2148-2160.

Snider, R. S., and Stowell, A. (1944). Receiving areas of tactile, auditory, and visual systems in the cerebellum. J. Neurophysiol. 7, 331-358.
Spencer, R. M. C., Zelaznik, H. N., Diedrichsen, J., and Ivry, R. B. (2003). Disrupted timing of discontinuous but not continuous movements by cerebellar lesions. Science 300, 1437-1439.

Sumbre, G., Muto, A., Baier, H., and Poo, M.-M. (2008). Entrained rhythmic activities of neuronal ensembles as perceptual memory of time interval. Nature 456, 102-106.

Teki, S., Grube, M., Kumar, S., and Griffiths, T. D. (2011). Distinct neural substrates of duration-based and beat-based auditory timing. J. Neurosci. 31, 3805-3812.

Treisman, M. (1963). Temporal discrimination and the indifference interval: implications for a model of the "internal clock." Pyschol. Monogr. 77, 1-31.

van Rijn, H., Kononowicz, T. W., Meck, W. H., Ng, K., and Penney, T. B. (2011). Contingent negative variation and its relation to time estimation: a theoretical evaluation. Front. Integr. Neurosci. 5:91. doi: 10.3389/fnint.2011.00091

Walberg, F. (1956). Descending connections to the inferior olive. An experimental study in the cat. J. Comp. Neurol. 104, 77-173.

Welsh, J. P., Lang, E. J., Sugihara, I., and Llinás, R. (1995). Dynamic organization of motor control within the olivocerebellar system. Nature 374, 453-457.

Wiener, M., Turkeltaub, P., and Coslett, H. B. (2010). The image of time: a voxel-wise meta-analysis. Neuroimage 49, 1728-1740.

Wing, A. M., and Kristofferson, A. B. (1973). The timing of interresponse intervals. Percept. Psychophys. 13, 455-460.

Wu, X., Ashe, J., and Bushara, K. O. (2011). Role of olivocerebellar system in timing without awareness. Proc. Natl. Acad. Sci. U.S.A. 108, 13818-13822.

$\mathrm{Xu}$, D., Liu, T., Ashe, J., and Bushara, K. O. (2006). Role of the olivocerebellar system in timing. J. Neurosci. 26, 5990-5995.

Yarom, Y., and Cohen, D. (2002). The olivocerebellar system as a generator of temporal patterns. Ann. N. Y. Acad. Sci. 978, 122-134.

Yee, W., Holleran, S., and Jones, M. R. (1994). Sensitivity to event timing in regular and irregular sequences: influences of musical skill. Percept. Psychophys. 56, 461-471.

Yeterian, E. H., and Pandya, D. N. (1998). Corticostriatal connections of the superior temporal region in rhesus monkeys. J. Comp. Neurol. 399, 384-402. 
Yizhar, O., Fenno, L. E., Davidson, T. J., Mogri, M., and Deisseroth, K. (2011). Optogenetics in neural systems. Neuron 71, 9-34.

Conflict of Interest Statement: The authors declare that the research was conducted in the absence of any commercial or financial relationships that could be construed as a potential conflict of interest.

Received: 02 December 2011; paper pending published: 07 December 2011; accepted: 13 December 2011; published online: 03 January 2012.

Citation: Teki S, Grube $M$ and Griffiths TD (2012) A unified model of time perception accounts for durationbased and beat-based timing mechanisms. Front. Integr. Neurosci. 5:90. doi: 10.3389/fnint.2011.00090
Copyright $\odot 2012$ Teki, Grube and Griffiths. This is an open-access article distributed under the terms of the Creative Commons Attribution Non Commercial License, which permits non-commercial use, distribution, and reproduction in other forums, provided the original authors and source are credited. 